\title{
MENTAL DISTURBANCES AND PERSONALITY TRAITS OF PATIENTS WITH POLYCYSTIC OVARY SYNDROME (PCOS)
}

N. Ilina1, T.V. Dovzhenko1, E.E. Grodnitskaya², A.E. Bobrov³.

${ }^{1} \mathrm{~V}$. Serbsky National Research Centre for Psychiatry and Narcology, Dept. of Clinical Psychology and Psychotherapy, Moscow, Russia.

${ }^{2}$ Centre of Family Planning and Reproduction-Moscow City health protection Department, Outpatient dept., Moscow, Russia.

${ }^{3} \mathrm{~V}$. Serbsky National Research Centre for Psychiatry and Narcology, Dep. of Consultative and Distance Psychiatry, Moscow, Russia.

Objectives: The aim was to study mental disturbances and personality variants of Russian patients with PCOS.

Background: Although interrelations between PCOS and mental disorders are recognized, little is known about personality of PCOS patients. The results of recent Turkish research, based on the national version of MMPI, suggested that women with PCOS had significantly higher elevation scores on scales $\mathrm{D}, \mathrm{Hy}, \mathrm{Pt}$ and $\mathrm{Ma}$ compared with the controls [Ozcan Dag Z. et al., 2015].

Materials and Methods: The study involved 114 women (median age 27 years) with PCOS (ESHRE/ASRM criteria) and 30 healthy controls (median age 26 years). All participants were examined by a psychiatrist and completed the Russian-language version of MMPI.

Results: The MMPI data of 96 women with PCOS and 22 healthy controls met the validity criteria and were used in analysis. PCOS patients had significantly higher scores on Scale Mf, lower scores on scales $\mathrm{Pd}$ and Sc $(p<0,05)$. Mental disorders (ICD-10) were diagnosed in $69 \mathrm{PCOS}$ patients. These women showed significant elevation on scales $\mathrm{D}, \mathrm{Pa}$, $\mathrm{Pt}$ and $\mathrm{Si}$ compared to mentally healthy patients $(p<0,05)$. We divided PCOS patients in 4 groups $(G)$ according to the results of factor analysis of MMPI data: G1 - "Anxious and depressed", G2 - "Masculine", G3 "Hypomanic" and G4 - "Sensitive". The rate of mental disorders in G2 and G3 was about $56 \%$, in $\mathrm{G} 1$ and $\mathrm{G} 4$ exceeded $84 \%$.

Conclusions: Majority of women suffering from PCOS are prone to depression and anxiety. There are 4 personality variants of PCOS patients, which are differently related to mental disorders.

Key words: PCOS, personality traits, mental disturbances
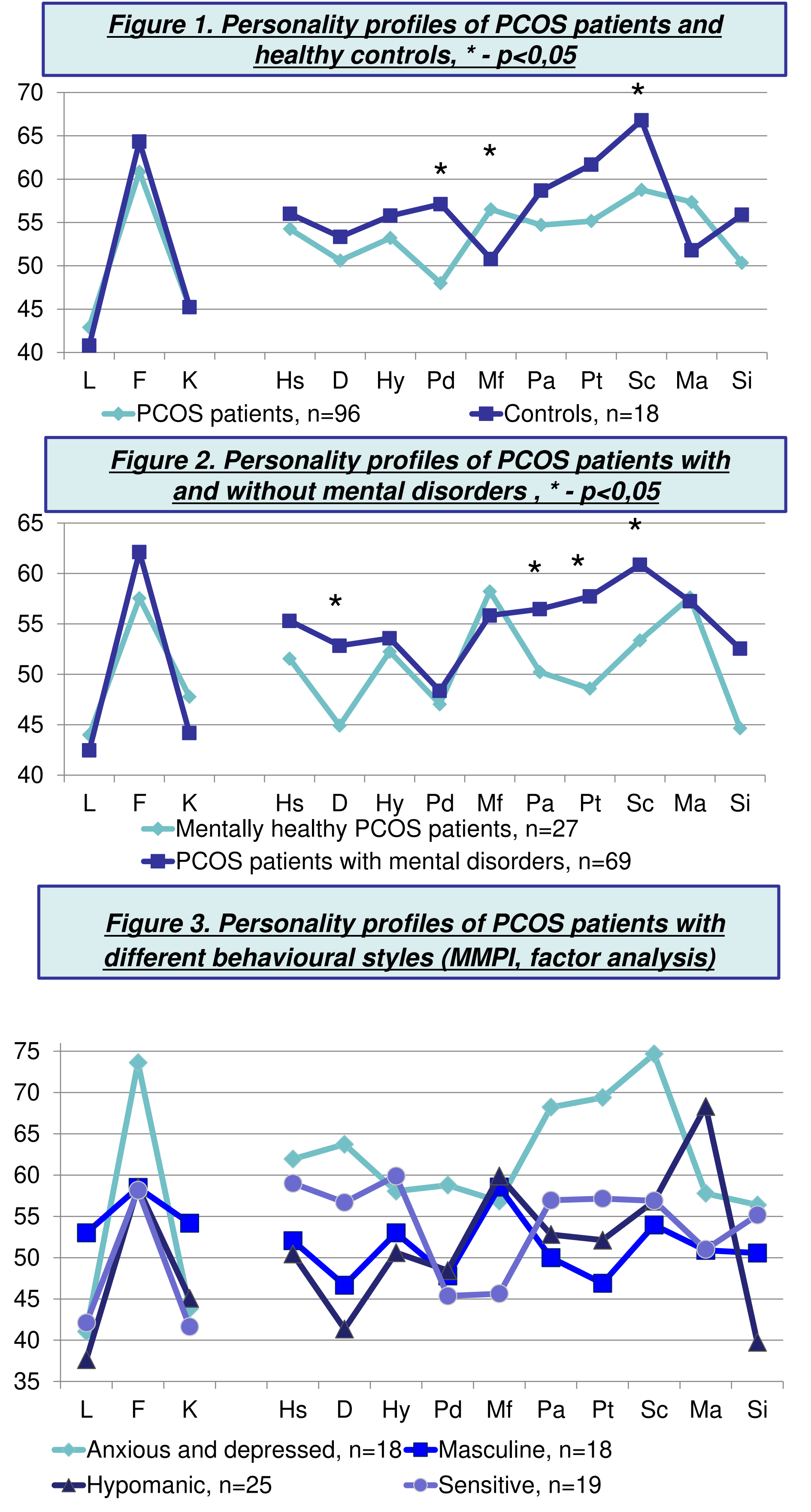

Table 1. The rate of mental disorders in PCOS patients,

( $X 2 p<0,05 ; N$ number of patients in the group; $n$-number of patient with mental disorders)

\begin{tabular}{|l|l|l|l|l|}
\hline MMIL profile variants & $\mathrm{N}$ & $\mathrm{n}$ & $\%$ & \\
\hline G1. Anxious and depressed & 18 & 16 & 88,9 & RDD $(38,9 \%, \mathrm{n}=7), \mathrm{GAD}(16,7 \%, \mathrm{n}=3), \mathrm{BD}(16,7 \%, \mathrm{n}=3)$ \\
\hline G2. Masculine & 18 & 10 & 56,0 & RDD $(22,2 \%), \mathrm{GAD}(11,1 \%)$ \\
\hline G3. Hypomanic & 25 & 14 & 56,6 & GAD (24,0\%), BD (16,0\%) \\
\hline G4. Sensitive & 19 & 16 & 84,2 & $\begin{array}{l}\text { RDD }(31,6 \%, \mathrm{n}=6), \text { GAD }(26,3 \%, \mathrm{n}=5), \text { Bulimia (15,8\%, } \mathrm{n}=3), \mathrm{DE}(10,5 \% \text {, } \\
\mathrm{n}=2)\end{array}$ \\
\hline
\end{tabular}

RDD - Recurrent Depressive Disorder, GAD - Generalized Anxiety Disorder, BD - Bipolar Disorder, DE - Depressive Episode 